\title{
Burdur Halk Pazarlarından Toplanan Beyaz Peynirlerde Patojen Candida spp. Varlığının Belirlenmesi
}

\author{
Özen Yurdakul' ${ }^{1}$ Erhan Keyvan'1, Tuğba Ersoy ${ }^{2}$ \\ ${ }^{1}$ Mehmet Akif Ersoy Üniversitesi, Veteriner Fakültesi, Besin Hijyeni ve Teknolojisi Anabilim Dal, Burdur \\ ${ }^{2}$ Mehmet Akif Ersoy Üniversitesi, Veteriner Fakültesi, Patoloji Anabilim Dall, Burdur
}

Geliş Tarihi / Received: 01.06.2016, Kabul Tarihi / Accepted: 21.09.2016

\begin{abstract}
Özet: Mayalar, gıdaların kalite ve güvenliğini etkileyen gıda endüstrisi için oldukça önemli mikroorganizmalar olup gıdalarda bozulmalara yol açabilirler. Candida türleri hastane enfeksiyonlarında önemli bir yere sahip iken son yıllarda gıdalar vasıtasıyla da insanlara bulaşabilmektedir. Bu çalışma ile halk pazarlarından toplanan peynirlerde patojen Candida türlerinin varlığının araştırılması amaçlandı. Analiz edilen 100 adet peynir örneğinin 84 (\%84)'ünde patojen Candida spp. pozitif olarak bulundu ancak hiçbirinde C. albicans saptanamadı. Bu çalışmada API 20 C AUX Test Kit'i ile 103 adet izolatın tür ayrımı yapıldı. Elde edilen test kit sonuçlara göre izolatların \%14'ü C. krusei, \%5'i C. tropicalis olarak identifiye edildi. Gıda örneklerinin mikrobiyolojik incelemesinde toplam maya ve küf sayısı ile birlikte patojen mayaların varlığına yönelik analizlerin de yapılması toplum sağlığı açısından yararlı olacağı sonucuna varıldı.
\end{abstract}

Anahtar Kelimeler: Beyaz peynir, patojen Candida spp., mantar, maya.

\section{Determination of Pathogen Candida spp. in White Cheese Collected from Burdur's Public Bazaars}

\begin{abstract}
Yeasts are very important microorganisms for the food industry that affects food quality and safety and yeasts may lead to spoil of the foods. The goal of this study was to evaluate the incidence of pathogen Candida spp. collected from cheese samples in public bazaar. Candida species are important for hospital infections which have been able to infect humans by food in recent years. Candida spp. were positive $84 \%$ of 100 cheese samples. In this study we were isolated 103 isolate which were identified with API 20 C AUX Test Kit. According to test kit results, C. albicans wasn't isolated any cheese samples and $14 \%$ were identified as C. krusei, $5 \%$ were identified as C. tropicalis from Candida spp. positive cheese samples. As a result, microbiological analysis of food samples should be made not just for the total number of mold, the samples should also be tested for the presence of pathogenic yeast it would be beneficial for public health.
\end{abstract}

Keywords: Fungi, pathogen Candida spp., white cheese, yeast.

\section{Giriş}

Mayalar, gıdaların kalite ve güvenliğini çeşitli şekillerde etkileyen gıda endüstrisi için oldukça önemli mikroorganizmalardır. Geleneksel olarak ekmek, bira ve şarap üretiminde kullanılırlar. Ayrıca bazı mayalar peynirlerin olgunlaştırılması ve ürünlere özgü karakterler kazandırılması amacıyla starter kültür olarak da kullanılmaktadır [11,18].

Candida spp.'ler Ascomycetes grubuna ait kommensal ökaryötik maya türleridir. Mayalar çevre, insan ve diğer memelilerde bulunabilirler [20]. Özellikle memelilerde gastrointestinal ve genitoüriner sistem mukoza florasinda bulunurlar [14]. Baz1 maya türleri gida güvenliğini olumsuz yönde etkileyerek firsatçı patojen olarak enfeksiyonlara neden olabilirler [1,9]. Patojen Candida türleri C. albicans ve Candida non-albicans türleri olarak da sinıflandırılmaktadır. Patojen Candida türleri içinde yer alan C. albicans insanlarda oral ve sistemik kandidiyasise neden olan en yaygin ve en patojen türdür $[8,33,38]$. Candida non-albicans türleri arasinda $C$. krusei, C. tropicalis, C. guilliermondi, C. lusitaniae, C. parapsilosis ve C. dubliniensis yer almaktadır. Süt sektörü açısından yüksek prevalans ve patojeniteye sahip patojen Candida türleri arasında klinik öneme sahip olan türler C. albicans, $C$. krusei ve $C$. tropicalis' tir [22].

Peynir mikrofloras1 peynirin tat, lezzet, aroma ve tekstür gibi yapılarını etkileyen en önemli bileşenlerindendir [2]. Bu kompleks mikroflorada 
bakteri, maya, küf gibi mikroorganizmalar bulunabilmektedir [5,32]. Peynirde bulunan mikroorganizmaların çeşitliliği ve sayısı; sütün mikrobiyal kalitesine, süte uygulanan işlemlere, peynirin olgunlaştırılması sırasındaki nem ve sıcaklığa bağlı olarak değişiklik gösterebilir [34].

Bazı Candida türleri gıdaların üretim prosesinde kullanılırken bazıları ise gidanın bozulmasında etkili olmaktadır. Bunun yanında Candida türleri et ve süt ürünlerinde starter kültür olarak da kullanılabilmektedir. Proteolitik, glikosidaz ve pektinolitik aktivite sonucu üretilen sekonder metabolitler ile lipolitik aktivite, üreaz aktivitesi, ozmotolerans, geniş üreme aralığ 1 , etanole tolerans ve düşük su aktivitesi gibi özelliklerinden gıda işlemlerinde yararlanılmaktadır [12,29].

Patojen Candida spp. beşeri hekimlikte sorun yaratmakta ve $C$. albicans, $C$. tropicalis ve $C$. krusei'ye bağlı infeksiyonlarda bir artış gözlenmektedir. Veteriner hekimlikte de Candida spp. özellikle son yıllarda mastitis etkeni olarak karşımıza çıkmaktadır [4]. Kontamine sütlerin 1sıl işlem uygulanmadan kullanılması ya da ürün haline getirilmesi, kötü koşullarda üretim, paketleme ve satışa bağlı olarak insanlar gidalar ile enfeksiyona yakalanmaktadir [20,21].

Patojen Candida türlerinin gidalarda varlığ 1 durumunda hastalık oluşturabileceği çoğu araştırmacı tarafından göz ardı edilen bir konudur. $\mathrm{Bu}$ çalışma ile pazarlardan toplanan beyaz peynirlerde patojen Candida türlerinin varlığının araştırılması amaçlanmıştır.

\section{Materyal ve Metot}

Burdur ili semt pazarlarından Ocak 2014-Aralık 2014 tarihleri arasinda toplanan 100 adet beyaz peynir örneği soğuk zincir altında laboratuvara getirildi. Her bir gıda örneği aseptik koşullar altında steril plastik torbalara 10'ar g olacak şekilde tartıld1. Üzerine $90 \mathrm{ml}$ steril peptonlu su $(\% 0.1)$ ilave edildikten sonra 1-2 dakika süre ile homojenizatörde (iul, Spain) homojenize edildi. Homojenat $10^{-8}$ desimal sulandırmaya kadar hazırlanarak CHROMagar Candida (CHROMagar Candida, USA) besiyerine ekim yapıld1. Petriler $37^{\circ} \mathrm{C}$ 'de 48 saat inkübasyona bırakıldı. İnkubasyon sonunda yeşil koloniler Can- dida albicans, pembe zon ile çevrili mavi koloniler Candida tropicalis, pembe koloniler Candida krusei, beyazdan leylak rengine doğru değişen koloniler diğer türler olarak değerlendirildi [19].

Peynirlerde toplam aerob bakteri yükünü tespit etmek amaciyla Plate Counte Agar'a (PCA) (Merck, 1.05463$) 30^{\circ} \mathrm{C}^{\prime}$ de $22-24$ saat, genel maya-küf sayılarının tespiti amaciyla Patato Dextrose Agar'a (PDA) (Merck 1.10130) $24^{\circ} \mathrm{C}$ 'de 4-5 gün inkübasyona birakıld1 [13].

\section{API testi ile doğrulama}

Elde edilen Candida spp. şüpheli izolatlar API 20 C AUX Test Kit (bioMérieux, France) ile üretici direktiflerine göre doğruland 1 [28].

\section{Bulgular}

$\mathrm{Bu}$ araştırmada, 100 adet beyaz peynir örneğinin 84 (\%84)'ünde Candida spp. pozitif olarak bulundu. Peynir örneklerinin hiçbirinde C. albicans saptanamad. Beyaz peynir örneklerinden elde edilen 103 adet şüpheli izolata tür ayrımı amacıyla API 20 C AUX Test Kit'i uyguland. API 20 C AUX Test Kit'i sonuçlarına göre izolatların \%14'ü C. krusei, $\% 5$ 'i C. tropicalis olarak doğruland. Analizlere ait mikrobiyolojik veriler incelendiğinde; PCA'da üreyen toplam aerob mezofil bakteri sayısının ortalama 8,42 $\pm 0,13 \log \mathrm{kob} / \mathrm{g}$, PDA'da üreyen maya küf sayısinin ortalama 7,56 $\pm 0,14 \log \mathrm{kob} / \mathrm{g}$, CHROMagar Candida'da üreyen Candida spp. sayısının ise

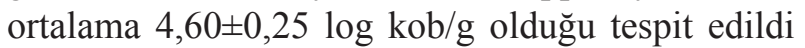
(Tablo 1).

Tablo 1. Peynir örneklerinde maya-küf, aerob mezofil genel canlı sayısı ve Candida spp. sayıları (log cfu g-1).

\begin{tabular}{lccc}
\hline & $\begin{array}{c}\text { Maya küf } \\
\text { sayısı }\end{array}$ & $\begin{array}{c}\text { Candida spp } \\
\text { sayısı }\end{array}$ & $\begin{array}{c}\text { Aerob mezofil } \\
\text { genel canlı sayısı }\end{array}$ \\
\hline PDA & CHROMagar Candida & PCA \\
Min & 2,20 & 100 & 100 \\
Max & 10,18 & 0,00 & 3,20 \\
$\mathrm{X} \pm \mathrm{Sx}$ & $7,56 \pm 0,14$ & $4,60 \pm 0,25$ & 11,00 \\
\hline
\end{tabular}

$\mathrm{x}$ : Ortalama, Sx: Standart hata, n: pozitif numune sayıs1

PDA: Patato Dextrose Agar

PCA: Plate Count Agar 


\section{Tartışma ve Sonuç}

Beyaz peynirde toplam aerob mezofil canlı bakteri sayısını etkileyen pek çok faktör bulunmaktadır. Beyaz peynir yapımında kullanılan sütün pastörize edilmemesi, hijyenik kurallara uyulmaması ve peynirin olgunlaştırılmadan taze olarak tüketime sunulması gibi sebepler peynirin mikrobiyolojik kalitesini etkilemektedir. Yaptığımız çalışma sonuçlarına göre; toplam aerob mezofil bakteri sayısının ortalama 8,42 $\pm 0,13 \log \mathrm{kob} / \mathrm{g}$ olarak saptanmıştır. Sert ve Kıvanç [30] Erzurum yöresinde yapılan bir çalışmada taze peynir örneklerindeki toplam aerob

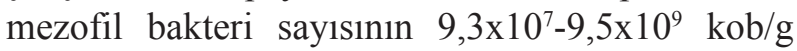
olduğu belirtilmiştir. Kurşun ve ark. [15] Burdur İli'nde küçük ölçekli süt mandıralarından topladıkları 100 adet beyaz peynir örneğinde toplam aerob mezofil bakteri sayısin $4,6 \times 10^{6}$ ile $1,0 \times 10^{9} \mathrm{kob} / \mathrm{g}$ değerleri arasında olduğunu saptamıştır. Yalçın [37] tüketime sunulan 50 adet salamura beyaz peynirde ortalama $2,7 \times 10^{8} \mathrm{kob} / \mathrm{g}$ toplam aerob mezofil bakteri saptamıştır. Çelik ve ark.[6] salamura beyaz peynir örneklerinde ortalama toplam aerobik mezofilik bakteri sayısın $8,9 \times 10^{7} \mathrm{kob} / \mathrm{g}$ olarak bildirmiştir. Uğur [35] Muğla'da yaptığı çalışmada beyaz peynirlerdeki toplam aerob mezofil bakteri sayısını $1,8 \times 10^{6}-6,0 \times 10^{8} \mathrm{kob} / \mathrm{g}$ değerleri arasında olduğunu saptamıştır. Çalışma sonuçları bulduğumuz sonuçlara benzerlik göstermektedir.

Beyaz peynirlerde toplam maya-küf sayısına bakıldığında yaptığımız çalışmada maya küf sayısinın ortalama 7,56 $\pm 0,14 \log \mathrm{kob} / \mathrm{g}$ olarak bulundu. Kurşun ve ark. [16] yaptıkları bir çalışmada küçük ölçekli süt mandıralarından temin ettikleri beyaz peynir örneklerinin \% 20'sinde toplam maya-küf sayısın $10^{4}-10^{5} \mathrm{kob} / \mathrm{g}$ düzeyinde olduğunu belirtmişlerdir. Uğur [35] incelediği peynir örneklerinde maya ve küf sayıs1 $3,7 \times 10^{3}-3,9 \times 10^{6} \mathrm{kob} / \mathrm{g}$ arasında,

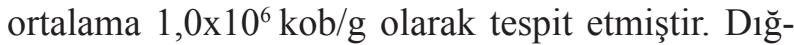
rak ve ark. [7] peynir örneklerindeki maya ve küf sayısının $2,2 \times 10^{2}-8,3 \times 10^{6} \mathrm{kob} / \mathrm{g}$ değerleri arasında değiştiği, ortalama sayının $1,0 \times 10^{6} \mathrm{kob} / \mathrm{g}$ olduğu belirtilmiştir. Sert ve Kıvanç [30] Erzurum'da satışa sunulan beyaz peynirlerdeki toplam maya ve küf sayısının ortalama olarak $2,6 \times 10^{6} \mathrm{kob} / \mathrm{g}$ olduğu belirtilmiştir. Çalışma sonuçlarımızın diğer sonuçlardan daha yüksek olduğu saptanmıştır.
Çiğ sütten üretilen süt ürünleri, mayaları da içeren birçok patojen mikroorganizmanın taşınmasında ve potansiyel sağlı riski oluşturması bak1mından gida güvenliğini olumsuz etkilemektedir $[17,21,25]$. Hayvanlarda meme enfeksiyonlarındaki patojen Candida türlerinin varlığının artması süt ürünlerini de bu patojen bakımından riskli hale getirmektedir [4,26].

Bu çalışmada toplanan 100 adet peynir örneğinin 84 (\%84)'ünde Candida spp. pozitif olarak tespit edilmiştir. Yapılan ekim sonuçları incelendiğinde ise toplanan örneklerin önemli bir kısmında maya ve küf varlığına rastlanmıştır (Tablo 1). Wanderley ve ark. [36] geleneksel olarak üretilen 45 artisanal peynirinin \%2.4'ünde $C$. albicans, \% 79.3'ünde $C$. krusei ve \% 6.0'sında C. tropicalis olduğunu bildirmiştir. Candida parapsilosis bazı peynirlerden (İsveç tipi peynir, mavi peynir ve çedar peyniri) izole edilen ve invaziv kandidiyazis oluşturan önemli bir Candida türü olarak tespit edilmiştir. Ancak gıda kaynaklı bir risk belirtilmemiştir [23]. C. parapsilosis bitki, toprak, su gibi çevresel kaynaklardan da izole edilmiştir [24] "Manteca" adı verilen İtalyan tipi bir peynirin dominant florasında bulunmuştur [31]. Türkiye'de yapılan bir çalışmada; toplanan 100 adet peynir örneğinin \%7.0'sinde $C$. albicans, $\% 12$ 'sinde $C$. krusei ve \% 3.0'ünde C. tropicalis olduğu saptanmıştır [16].

Peynirlerde maya ve küfler ile kontaminasyon starter kültür, hava, ekipman, salamura suyu, personel gibi çeşitli yollar ile olabilir [3,25,27]. Bazı mayalar tat, lezzet ve görünüm gibi yararlı özellikleri ile etkili olurken bazıları da peynirlerde bozukluklar meydana getirebilir. Gıda kaynaklı enfeksiyonlara sebep olabilir. Medikal önemi olan ve peynirlerden izole edilen Candida albicans, Candida tropicalis, C. krusei ve C. glabrata gibi Candida türleri de bulunmaktadır $[8,10,36]$.

Mikrobiyolojik analizlerde kullanılan besiyerleri toplam maya ve küf sonucuna yönelik olup patojen maya ve küfleri ayırt edememektedir. Gıda örneklerinin mikrobiyolojik incelemesinde; toplam maya ve küf sayısı ile birlikte patojen mayaların varlığına yönelik incelemeler de toplum sağlığı aç1sindan önemlidir. $\mathrm{Bu}$ verilere göre pazarlarda sat1lan peynirlerin Candida spp. yönünden büyük bir risk oluşturduğu ve toplumun bu risk bakımından 
bilgilendirilmesi ve bu alana yönelik kapsamlı çalışmalar yapılması gerektiği sonucuna varılmıştır.

\section{Kaynaklar}

1. Banjara N, Suhr, MJ, Hallen Adams HE, (2014). Diversity of Yeast and Mold Species from a Variety of Cheese Types. Curr Microbiol, 70, 792-800.

2. Beresford TP, Fitzsimons N, Brennan NL, Cogan TM, (2001). Recent advances in cheese microbiology. Int Dairy J, 11, 259-274.

3. Borelli BM, Ferreira EG, Lacerda ICA, Franco GR, Rosa CA, (2006). Yeast populations associated with the artisanal cheese produced in the region of Serra da Canastra, Brazil. World J Microbiol Biotechnol, 22, 1115-1119.

4. Crawshaw WM, Macdonald NR, Duncan G, (2005). Outbreak of Candida rugosa mastitis in a dairy herd after intramammary antibiotic treatment. Vet Res, 156, 812-813

5. Creppy EE, (2002). Update of survey, regulation and toxic effects of mycotoxins in Europe. Toxicol Lett, 127, 19-28.

6. Çelik S, Özdemir C, Özdemir S, Sert S, (1998). Diyarbakır yöresinde tüketime sunulan salamura beyaz peynir örneklerinin mikrobiyolojik, fiziksel ve kimyasal özellikleri. V. Süt ve Süt Ürünleri Sempozyumu, Geleneksel Süt Ürünleri. Ankara: Milli Prodüktivite Yayınları, 621, 351-360.

7. Dığrak M, Yılmaz Ö, Çelik S, Özçelik S, (1996). Elazı̆̆’da satışa sunulan taze beyaz peynirlerin mikrobiyolojik kalitesi ve yağ asitleri analizi. Turk J Biology, 20, 221-230.

8. El-Sharoud WM, Belloch C, Peris D, Querol A, (2009). Molecular identification of yeasts associated with traditional Egyptian dairy products. J Food Sci, 74, M1-M6.

9. Fleet GH, (2007). Yeasts in foods and beverages: impact on product quality and safety. Curr Opin Biotechnol, 18, 1705.

10. Gadaga TH, Mutukumira AN, Narvhus JA, (2000). Enumeration and identification of yeasts isolated from Zimbabwean traditional fermented milk. Int Dairy J, 10, 459-466.

11. Haasum I, Nielsen PV, (1998). Physiological characterization of common fungi associated with cheese. J Food Sci, 63, 157-161.

12. Hommel RK, (2014). Candida. Batt CA, Torterollo ML. eds. Encylopedia of Food Microbiology. Academic Press Inc, San Dieogo. p.367-374.

13. Koburger JA, Marth EH, (1984). Yeasts and Moulds. Speck ML. eds. Compendium of Methods for the Examination of Foods A.P.H.A. Washington D.C. p.197-202

14. Kumamoto CA, (2011). Inflammation and gastrointestinal Candida colonization. Curr Opin Microbiol, 14, 386-391.

15. Kursun O, Kirdar SS, Keyvan E, Guner A, (2011). Microbiological quality of white pickled cheese produced in small plants in Burdur, Turkey. J Food Agric and Environ, 9(2), 110-112.

16. Kurşun Ö, Kale SA, Kırdar SS, (2008). Türkiye'deki Peynirlerde Candida albicans Varlığı. VIII. Ulusal Veteriner
Mikrobiyoloji Kongresi (Uluslararası Katılımlı). 07-09 Ekim, Yüzüncü Y1l Üniversitesi,Van.

17. Lavoie K, Touchette M, St-Gelais D, Labrie S, (2012). Characterization of the fungal microflora in raw milk and specialty cheeses of the province of Quebec. Dairy Sci Technol, 92, 455-468.

18. Loretan T, Viljoen BC, Mostert JF, Vogel AM, Jordaan HF, (1998). A preliminary study of the diversity and technological properties of indigenous traditional South African fermented milk. Jakobsen M, Narvhus J and Viljoen BC. eds. Yeasts in the dairy industry: positive and negative aspects. Proceedings of the symposium organized by Group F47; 1996 Sept 2-3; Brussels, Belgium. p.178-82.

19. Mathavi S, Sasikala G, Kavitha A, Indra PR, (2016). CHROMagar as a primary isolation medium for rapid identification of Candida and its role in mixed Candida infection in sputum samples Indra Priyadarsini. Indian J Microbiol Res, 3(2), 141-144.

20. McManus BA, Coleman DA, (2014). Molecular epidemiology, phylogeny and evolution of Candida albicans. Infect Genet Evol, 21, 166-168.

21. Melville PA, Benites NR, Ruz-Peres M, Yokoya E, (2011). Proteinase and phospholipase activities and development at different temperatures of yeasts isolated from bovine milk. J Dairy Res, 78, 385-390.

22. Miceli MH, Díaz JA, Lee SA, (2011). Emerging opportunistic yeast infections. Lancet Infect Dis, 11, 142-151.

23. Moran G, Coleman D, Sullivan D (2012). An introduction to the medically important Candida species. Calderone RA, Clancy CJ. eds. Candida and candidiasis, 2nd edn. ASM Press, New York, p.11-25.

24. Moran G, Stokes C, Thewes S, Hube B, Coleman DC, Sullivan D, (2004). Comparative genomics using Candida albicans DNA microarrays reveals absence and divergence of virulence-associated genes in Candida dubliniensis. Microbiol, 150, 3363-3382.

25. Mounier J, Goerges S, Gelsomino R, Vancanneyt M, Vandemeulebroecke K, Hoste B, et al, (2006). Sources of the adventitious microflora of a smear-ripened cheese. J Appl Microbiol, 101, 668-681.

26. O'Brien NM, O'Connor TP, O'Callaghan JO, Dobson ADW, (2004). Toxins in cheese. Fox PE, McSweeney PLH, Cogan TM, Guinee TP. eds. Cheese: Chemistry, Physics and Microbiology, vol 1, 3rd edn. Elsevier Academic Press, Amsterdam, p.562-571.

27. Pereira-Dias S, Potes ME, Marinho A, Malfeito-Ferreira M, Loureiro V, (2000). Characterisation of yeast flora isolated from an artisanal Portuguese ewes' cheese. Int J Food Microbiol, 60, 55-63.

28. Pincus DH, Coleman DC, Pruitt WR, Padhye AA, Salkin IF, Geimer M, Bassel A, Sullivan DJ, Clarke M, Hearn V, (1999). Rapid identification of Candida dubliniensis with commercial yeast identification systems. J Clin Microbiol, 37, 3533-3539.

29. Sengun IY, Yaman DB, Gonul SA, (2008). Mycotoxins and mould contamination in cheese: a review. World Mycotoxin J, 1, 291-298. 
30. Sert S, Kıvanç M, (1984). Erzurum piyasasında taze olarak tüketime sunulan beyaz peynirlerin kaliteleri üzerinde bir araştırma, Ankara Üniversitesi Ziraat Dergisi, 15, 79-89.

31. Suzzi G, Schirone M, Martuscelli M, Gatti M, Fornasari ME, Neviana E, (2003). Yeasts associated with Manteca. FEMS Yeast Res, 3, 159-166.

32. Swearingen PA, O'Sullivan DJ, Warthesen JJ, (2001). Isolation, characterization, and influence of native, nonstarter lactic acid bacteria on cheddar cheese quality. J Dairy Sci, 84, 50-59.

33. Thompson GR, Patel PK, Kirkpatrick WR, Westbrook SD, Berg D, Erlandsen J, Redding SW, Patterson TF, (2010). Oropharyngeal candidiasis in the era of antiretroviral therapy. Oral Surg Oral Med Oral Pathol Oral Radiol Endod, 109, 488-495.

34. Torkar KG, Teger SG, (2006). The presence of some pathogen micro organisms, yeasts and moulds in cheese samples produced at small dairy-processing plants. Acta Agric Slov, $88,37-51$.

35. Uğur A, (2001). Muğla halk pazarında satışa sunulan ev yapımı peynirlerin mikrobiyolojik özellikleri. Çevre Koruma Dergisi, 40, 3-8.

36. Wanderley L, Bianchin A, Arruda Teo CRP, Meneghello Fuentefria A, (2013). Occurrence and pathogenicity of Candida spp. in unpasteurized cheese. Braz J Biosci, 11, 145-148.

37. Yalçın S, (1987). Ankara ve yöresinde tüketime sunulan salamura beyaz peynirlerinin mikrobiyal ve kimyasal içerikleri ile duyusal nitelikleri arasındaki ilişki. Doğa TU Vet Hay Dergisi, 2, 189-198.

38. Zomorodian K, Haghighi NN, Rajaee N, Pakshir K, Tarazooie B, Vojdani M, Sedaghat F, Vosoghi M, (2011). Assessment of Candida species colonization and denturerelated stomatitis in complete denture wearers. Med Mycol, 49, 208- 211. 